\title{
Casa-grande e senzala, de Gilberto Freyre, na Itália: exemplos de escolhas tradutórias extraídos da análise paratextual
}

\section{Casa-grande e senzala by Gilberto Freyre in Italy: examples of translation choices from the paratextual analysis}

Nicoletta Cherobin

Universidade Federal do Ceará (UFC), Fortaleza / Brasil

nicoletta_chero@hotmail.it

Resumo: Este artigo tem como objetivo apresentar exemplos de escolhas tradutórias ligadas a um léxico tipicamente brasileiro evidenciadas a partir da análise de uma seleção de paratextos da versão italiana de Casa-grande e senzala: formação da família brasileira sob o regime de economia patriarcal (1933), de Gilberto Freyre, publicada com o título Padroni e schiavi e traduzida por Alberto Pescetto, em 1965, pela editora Einaudi. Para atingir este objetivo e embasar teoricamente este artigo, utilizaramse contribuições de teóricos dos Estudos da Tradução (TOROP, 2010; BAKER, 1998; VENUTI, 1999; GENTZLER, 1998), mas sobretudo dos estudos paratextuais (GENETTE, 1989; YUSTE FRIAS, 2010; TORRES, 2011). A análise de alguns paratextos selecionados (representados pela capa, os prefácios e o glossário) proporcionou a apresentação da ligação entre as traduções produzidas, da mesma obra, em diversos contextos culturais e geográficos: o estadunidense, o francês e o italiano. De fato, a produção de Padroni e schiavi conta com a contribuição dos intelectuais franceses da École des Annales [Escola dos Anais] e, indiretamente, do brasilianista Samuel Putnam, responsável pela tradução estadunidense usada como referência para a tradução francesa e, em seguida, a italiana. 
Como conclusão foi possível evidenciar também algumas caraterísticas meramente distintivas deste último contexto histórico e cultural de recepção.

Palavras-chave: Gilberto Freyre; Casa-grande e senzala; Padroni e schiavi; paratexto; tradução italiana.

Abstract: This article aims to present some example of translation choices of the Brazilian vocabulary encountered in some paratexts of the Italian version of Casa-grande e senzala: formação da família brasileira sob o regime de economia patriarcal (1933), written by Gilberto Freyre, which was published with the title Padroni e schiavi and translated by Alberto Pescetto in 1965 for Einaudi Editore. In order to achieve our goal as well as to support our theoretical basis for this article, we relied on some contributions of Translation Studies theorists (TOROP, 2010; BAKER, 1998; VENUTI, 1999; GENTZLER, 1998) and theorists of paratextual studies (GENETTE, 1989; YUSTE FRIAS, 2010; TORRES, 2011). The paratextual analysis, which consider the book covers, prefaces, and glossaries, provided the presentation with a connection among the translations of the same book carried out in different cultural and geographical contexts: the American, the French, and the Italian. In fact, the production of Padroni e schiavi contains contributions from the French intellectuals of Ecole des Annales and, indirectly, from the Brazilianist Samuel Putnam, responsible for the American version, which was used as reference both in the French translation and, after that, in the Italian version. Finally, it was possible to point out representative characteristics belonging specifically to this latter historical and cultural reception context.

Keywords: Gilberto Freyre; Casa-grande e senzala; Padroni e schiavi; paratexts; italian translation.

Recebido em 1 de março de 2016. Aprovado em 14 de junho de 2016. 
A produção intelectual de Gilberto Freyre no Brasil e no exterior demonstra a heterogeneidade dos influxos que permeiam a personalidade do autor pernambucano, que o tornam um intelectual extremamente complexo e, em alguns casos, controverso. Das dezenas de obras publicadas por ele, as traduzidas para o italiano foram realizadas entre a década de 50 e a de 70 do século XX. Além de Casa-grande e senzala são traduzidas e publicadas na Itália: Interpretazione del Brasile (1954); Nordeste: l'uomo e gli elementi (1970); Case e catapecchie: la decadenza del patriarcato rurale brasiliano e lo sviluppo della famiglia urbana (1972) e, enfim, Sociologia della medicina: breve introduzione allo studio dei suoi principi, metodi e con altre sociologie e altre scienze (1975). ${ }^{1}$

Por um lado, a presença de Gilberto Freyre na Itália pode ser considerada escassa, levando a pensar que a figura do intelectual brasileiro passou quase despercebida pela crítica italiana. Todavia, esta mesma ausência pode despertar muitas reflexões, como a hipótese de o seu sucesso ter sido mediado (e facilitado) pela publicação de obras diretamente em língua inglesa e por um grupo de intelectuais, em particular franceses, que promoveram sua difusão entre os especialistas do âmbito antropológico, sociológico e também médico da Europa inteira.

Em particular, a situação histórica e social geral da Itália, a partir do pós-guerra e até a década de 1980, deve ser considerada relevante para a análise dos elementos que favoreceram a chegada ao país do manuscrito e de outras quatro traduções. Posteriormente a essa época, as obras de Freyre param de ser traduzidas e difundidas, diminuindo, assim, pouco a pouco, aquele grande entusiasmo inicial que caracterizara as suas traduções, como enfatizou Fernand Braudel (1965, p. IX) no prefácio de Padroni e schiavi.

As mais recentes afirmações da jornalista Barbara Celarent (2010) reforçam este entusiasmo atribuído à formação histórica do Brasil, o qual, obviamente, não representa a perfeição, mas cresce e se fortalece a partir dos próprios males, inclusive o da escravidão:

\footnotetext{
${ }^{1}$ Traduções, respectivamente, de Brazil, an interpretation (New York: Alfred A. Knopf, 1945), Nordeste: aspectos da influência da cana sobre a vida e a paisagem do Nordeste do Brasil (Rio de Janeiro: José Olympio, 1937), Sobrados e mucambos: decadência do patriarcado rural e desenvolvimento do urbano (São Paulo: Companhia Editora Nacional, 1936), Sociologia da medicina: breve introdução ao estudo dos seus princípios, dos seus métodos e das suas relações com outras sociologias e com outras ciências (Lisboa: Fundação Calouste Gulbenkian, 1967).
} 
O desejo de Freyre de demonstrar a extraordinária fusão de culturas no Brasil o leva a infinitas discussões sobre comida, roupa, rituais religiosos e dança. Podemos sentir o cheiro de alguns tipos de corpos, a sedução da comida das mulheres, as marcas corporais das doenças venéreas endêmicas, a importância da cor vermelha, o calor e a indolência do meio-dia na Casa-grande. Ouvimos o som das rezas, os cantos das regiões do interior, a bagunça dos alunos, e o sussurro das canções de ninar. E, sobretudo, temos a realidade nua e crua (CELARENT, 2010, p. 337). ${ }^{2}$

Publicada em 1933, Casa-grande e senzala, de Gilberto Freyre, pode ser colocada entre as mais importantes obras de cultura brasileira em constante diálogo com diversas disciplinas, da sociologia à história, e da geografia à antropologia, sendo difundida em vários países, entre os quais Estados Unidos, França, Itália e Portugal. Segundo Vamireh Chacon (2001, p. 85), até o final do século XX, Casa-grande e senzala já apresentava mais de 40 traduções, superando Os sertões, de Euclides da Cunha, e o interesse por essa obra é ainda atual, muito embora ela tenha sido escrita há mais de oitenta anos, confirmando o que Antônio Candido (1995) já declarou: junto com Formação do Brasil contemporâneo (1934), de Caio Prado Júnior, e Raízes do Brasil (1936), de Sérgio Buarque de Holanda, a obra de Freyre reflete uma corrente inovadora, fornecendo um importante instrumento teórico, útil à elaboração de um retrato da realidade nacional brasileira (CANDIDO, 1995, p. 11).

Dentro de um objetivo mais amplo de pesquisa que pretende estudar e verificar a presença de Gilberto Freyre na Itália, neste artigo, apresentam-se exemplos de escolhas tradutórias e editoriais presentes nos paratextos selecionados da tradução italiana intitulada Padroni e schiavi, traduzida por Alberto Pescetto e publicada em 1965 pela editora Einaudi. Alguns dos elementos paratextuais analisados (como capa, notas,

\footnotetext{
2 "Freyre's desire to show the extraordinary melding of cultures in Brazil leads him into endless discussions of food, of clothing, of religious rituals, of dance. We hear of the smell of certain kinds of bodies, the lushness of women's diets, the bodily marks of the endemic venereal diseases, the importance of the color red, the heat and indolence of midday in the Big House. We hear the sound of prayers, the songs of the interior regions, the rhymes of schoolboy taunts, and the hum of lullabies. Above all, we get the sharp rasp of reality" (Tradução minha).
} 
prefácio e glossário) revelaram informações particularmente importantes, confirmando que a tradução não representa simplesmente um processo de substituição de elementos lexicais e gramaticais entre línguas, mas envolve uma extensa rede de fatores econômicos, históricos, (extra)textuais e socioculturais. Por isso, são exatamente estes elementos que assumem grande importância, permitindo refletir sobre estratégias tradutórias (BAKER, 1998), introduzindo, inclusive, novas chaves de leitura.

Uma destas chaves é introduzida por José Yuste Frías (2010), que, falando em paratradução, observa como as escolhas tradutórias e editoriais levam à produção de textos com características muito específicas, dependendo do contexto de produção. Com este conceito, paralelamente ao de paratexto, o autor traz uma noção mais ampla de tradução, que vai além do mero texto. De fato, como ele mesmo afirma:

As novas teorias sobre tradução estão cientes que a tradução representa, antes de tudo, uma pratica social, política e cultural que implica complexas operações de transformação textual que diferem em função do momento e do lugar. Traduzir nunca pode ser uma atividade mecânica, pois depende das condições políticas, econômicas, sociais e culturais onde se geram os textos (YUSTE FRÍAS, 2005, p. 59-60). ${ }^{3}$

No caso analisado neste artigo, as reflexões propostas por Yuste Frías (2005) permitiram evidenciar como o particular momento histórico pós-II Guerra Mundial teria influenciado a difusão/circulação da mencionada tradução de Casa-grande e senzala na Itália e também quão fundamental teria sido a contribuição dada pela tradução estadunidense de Samuel Putnam, The masters and the slaves (1946), e pela francesa, proposta pelo sociólogo Roger Bastide com o título Maîtres et esclaves (1952).

\footnotetext{
3 "Las nuevas teorías de la traducción son conscientes de que la traducción es, ante de todo, una práctica social, política e cultural que implica complejas tareas de transformación textual que varían en función del momento y del lugar. Traducir nunca puede ser una actividad mecánica sino que depende de las condiciones políticas, económicas, sociales y culturales en que se generan los textos" (Tradução minha).
} 
Antes de tudo, o texto produzido nos Estados Unidos faz parte de um programa do governo que incentivava a aproximação política e cultural entre aquele país e o Brasil. De fato, entre a Segunda Guerra Mundial e a Guerra Fria, a literatura estrangeira traduzida foi vista pelo governo dos Estados Unidos como ferramenta para conhecer a cultura do outro e como instrumento para fortalecer alianças políticas. A política da "Boa Vizinhança" promovida por Franklin Roosevelt é um exemplo disso: a editora estadunidense Knopf, como outras, recebia ajudas governamentais para traduzir e publicar obras estrangeiras. A tradução francesa, Maîtres et esclaves, foi publicada pela famosa editora Gallimard e, além do sociólogo Roger Bastide, amigo e colega de Freyre, como autor da tradução, esta conta com a participação dos intelectuais da Escola dos Anais: Luciene Febvre e Fernand Braudel.

Em relação à tradução italiana de Casa-grande e senzala foi particularmente rica a análise de alguns paratextos que, de praxe, se dividem em: índices morfológicos (representados pela capa, contracapa, páginas de rosto) e discursos de acompanhamento (notas, prefácios, posfácios e glossários), segundo as indicações da teórica Marie-Hélène C. Torres (2011). Devido a isso, serão apresentados, a título de exemplo, a capa e, logo em seguida, a estrutura e o conteúdo dos prefácios - à primeira edição e à edição italiana -, a introdução do intelectual francês Fernand Braudel e, enfim, o glossário produzido pelo tradutor italiano. É interessante o fato de estas que Peeter Torop chama de "ramificações do texto" (TOROP, 2010) proporcionarem a apresentação de uma seleção de estratégias tradutórias e editoriais desenvolvidas por Alberto Pescetto e pela editora Einaudi sobretudo em âmbito semântico-lexical, particularmente no que diz respeito aos termos mais ligados à tradição cultural e à geografia brasileira e de difícil tradução.

Portanto, por detrás da escolha editorial e intelectual de publicar uma obra, também existem muitos elementos a se considerar. Graças à análise do primeiro elemento paratextual escolhido como objeto para este artigo, ou seja, a capa, será possível evidenciar alguns dados significativos sobre aspectos mais velados e interpretáveis da tradução, nos quais está envolvida a editora Einaudi. Fundada em Turim, a Einaudi é muito representativa de um delicado momento histórico, em nível internacional, assim como o eclético intelectual que traduziu o texto, Alberto Pescetto. 
Em relação às publicações dessa editora, ${ }^{4}$ as pesquisas revelaram quais e quantos autores brasileiros e latino-americanos foram traduzidos durante quase um século, dando visibilidade a um novo contexto literário na Itália, todavia secundário naquela época. Por exemplo, descobre-se que a mesma editora é responsável, na Itália, pela publicação dos primeiros dois textos que compõem a trilogia freyriana (Padroni e schiavi e Case e catapecchie) e ainda ocupou-se da publicação de obras de Jorge Amado, Carlos Drummond de Andrade, Mario e Oswald de Andrade e Darcy Ribeiro (EINAUDI, 2003, p. 1194). Entretanto, enquanto esses autores fazem parte (no índice por assuntos) da categoria "Letteratura Portoghese e Brasiliana" [Literatura Portuguesa e Brasileira], Freyre é inserido na categoria "Scienze Umane. Antropologia. Etnologia. Folklore" [Ciências Humanas. Antropologia. Etnologia. Folclore], na coletânea "Nuova Biblioteca Scientifica Einaudi" [Nova Biblioteca Científica Einaudi].

Em relação ao tradutor, Alberto Pescetto (Valparaíso, 1911-1981), cujo nome está indicado na capa da tradução italiana da obra analisada, também traduziu outras três obras freyrianas na década de 1970: Nordeste (1970), Case e catapecchie (1972) e Sociologia della medicina (1975). É reconhecido e apreciado como um intelectual expert em russo no Novecento italiano. Como tradutor, recebe a atenção de algumas das mais prestigiosas editoras italianas, como Bombiani, Mondadori, Adelphi, Einaudi e Feltrinelli, tendo publicado diversas obras entre os anos 60 e 80 do século passado. Traduz, a princípio, autores russos, como Čingiz Ajtmatov, Leonid Grossman, Veniamin Kaverin, Leonov Leonid, Vladimir Nabokov, Vasilij Rozanov, Lev Šestov, Andrej Sinjavskij e Lev Trockij. ${ }^{5}$ Todavia não se ocupa somente de traduções do russo, mas

\footnotetext{
${ }^{4}$ Resumidas em um significativo volume, Le edizioni Einaudi negli anni 1933-2003 (2003), que descreve todas as obras traduzidas a partir do ano de fundação da casa editora (1933) até a década passada e que possibilitou uma maior compreensão da sua história e do seu papel dentro do ramo editorial italiana.

${ }^{5}$ De Čingiz Ajtmatov, Giamilja e altri racconti (Milano: Mondadori, 1961); de Leonid P. Grossman, Dostoevskij artista (Milano: Bompiani, 1961); de Veniamin Kaverin, Lo scandalista, ovvero, le serate nell'isola Vasil'ev (Milano: Mondadori, 1970); de Leonov Leonid, La foresta russa (Milano: Mondadori, 1961); de Vladimir Vladimirovič Nabokov, Poesie (Milano: Il Saggiatore, 1962); de Vasilij Vasil'evič Rozanov, Foglie cadute (Milano: Adelphi, 1976) e L'apocalisse del nostro tempo (Milano: Adelphi, 1979 e 1988); de Lev Šestov, Sulla bilancia di Giobbe (Milano: Adelphi, 1991); de Andrej Donat'evič Sinjavskij, In difesa della piramide o contro Evtusenko (Milano: Jaca
} 
também do português. E as obras freyrianas publicadas por Giulio Einaudi representam seus primeiros passos no mundo lusófono. Logo em seguida ele se ocupa da tradução dos ensaios antropológicos de Darcy Ribeiro (1922-1997), publicados por Einaudi e Feltrinelli. ${ }^{6}$

Não é difícil supor que fossem poucos os intelectuais conhecedores da língua portuguesa na Itália e, tendo em vista a fama do intelectual nascido no Chile, assíduo viajante, é possível supor que foi escolhido pela editora Einaudi para enfrentar o desafio de traduzir uma obra realmente complexa como a freyriana. A presença numerosa de autores russos inseridos na coletânea intitulada Nuova Biblioteca Scientifica Einaudi, provavelmente orientou a escolha da editora. Apesar das críticas recebidas pelo fato de nunca ter publicado nada como autor, sua atividade como tradutor é muito apreciada por diversos intelectuais (DAVID, 2012).

Terminada a apresentação dos agentes envolvidos na tradução italiana de Casa-grande e senzala, procede-se à apresentação dos elementos que compõem o paratexto e permitiram encontrar um nexo entre as traduções da obra prima freyriana produzidas na Itália, França e Estados Unidos. De fato, como afirma Gentzler (1998, p. 139), um texto nunca é totalmente autônomo, mas está envolvido em uma série de relações com outros elementos de outros sistemas, seja no centro, seja na periferia do conjunto cultural. No caso de Padroni e schiavi isso se deve não somente à presença de diversos prefácios em apêndice, ${ }^{7}$ mas, sobretudo, à presença de um glossário que, como afirmado em nota pelo tradutor da obra, foi criado a partir da união de diversos dicionários

Book, 1967) e Pensieri improvvisi (Milano: Jaca Book, 1978); enfin, de Lev Trockij, Il giovane Lenin (Milano: Mondadori, 1971).

${ }^{6}$ Le Americhe e la civiltà (Torino: Einaudi, 1975); Il processo civilizzatore (Milano: Feltrinelli, 1973).

7 "Prefazione alla prima edizione Lisbona (1931), Pernambuco (1933)" [Prefácio à primeira edição Lisboa (1931), Pernambuco (1933)]; "Prefazione alla seconda edizione Recife (1934)" [Prefácio à segunda edição Recife (1934)]; "Una prefazione o quasi alla terza edizione (1938)" [Um prefácio ou quase à terceira edição (1938)]; "Prefazione alla quarta edizione, Rio (aprile 1942)" [Prefácio à quarta edição, Rio (abril de 1942)]; "Prefazione alla quinta edizione, Apipucos (marzo 1946)" [Prefácio à quinta edição, Apipucos (março de 1946)]; "Prefazione alla sesta edizione, Rio (gennaio 1949)" [Prefácio à sexta edição, Rio (janeiro de 1949)]; "Prefazione alla nona edizione, Apipucos (marzo 1957)" [Prefácio à nona edição, Apipucos (março de 1957)]. 
brasileiros e com o apoio da tradução francesa e da estadunidense (PESCETTO, 1965, p. 522).

Antes dos discursos de acompanhamento, um dos índices morfológicos mais representativos de um livro, a capa, apresenta-se extremamente sóbria, com uma borda cinza e um retângulo claro onde estão inseridas as informações relativas ao nome do autor, Gilberto Freyre, escrito em letras pretas maiúsculas e, logo em seguida, o título e subtítulo da obra: Padroni e schiavi - la formazione della famiglia brasiliana in regime di economia patriarcale, sempre no mesmo caráter. Essa capa parece não ser muito chamativa se comparada aos clássicos elementos tropicais, exóticos, presentes nas capas de algumas edições brasileiras da obra. ${ }^{8}$ Essa estratégia editorial parece atribuir certa cientificidade à tradução, dedicada provavelmente a um público específico. Em seguida, aparece a informação da presença de uma introdução escrita por Fernand Braudel e, enfim, o nome do tradutor. Diferenciar as duas figuras: aquela do tradutor e aquela do autor, informação presente, neste exemplar, desde a capa, enfatiza, de fato, o status de tradução, apesar de não estar presente nenhum tipo de referência ao Brasil ou à língua portuguesa. $\mathrm{O}$ verso da capa é completamente cinza, sem algum tipo de informação adicional, enquanto na lombada encontram-se o nome da editora, do autor, e o título da obra. Na parte inferior da capa colocam-se também o nome do editor Giulio Einaudi e o brasão que o representa.

Como já antecipado, a presença de uma introdução e de um glossário, especificamente criados para o público italiano, além da introdução do intelectual francês Fernand Braudel, denotam certo cuidado do autor brasileiro, assim como do tradutor e da editora, em acompanhar o leitor durante o longo e complexo caminho da leitura da obra.

Em ordem de aparição ao público italiano, todavia, encontrase primeiramente o prefácio escrito por Gilberto Freyre, entre Lisboa (1931) e Pernambuco (1933), em ocasião da primeira edição brasileira e presente praticamente em todas as traduções existentes nas Américas e na Europa (CHEROBIN, 2015). Este se alonga por cerca de 40 densas páginas onde transparece a importância deste elemento introdutório: sua utilidade tanto na análise paratextual quanto para a maior compreensão do texto propriamente dito (GENETTE, 1989) e do contexto brasileiro e internacional de produção da obra, ainda que

\footnotetext{
${ }^{8}$ Como, por exemplo a 50"a , proposta, em 2005, pela Global Editora.
} 
muitas vezes seja considerado supérfluo, pelo leitor comum ou pelo público mais especializado. Sua caraterística principal é claramente a de ter sido endereçado ao público brasileiro, ou seja, a um público que compartilha, em maior ou menor grau, o mesmo contexto geográfico e cultural do autor; mas apesar disso está carregado de notas, referências bibliográficas de ajuda ao leitor. Para o público estrangeiro representa ainda mais uma ferramenta indispensável, tendo em conta a abundância de referências linguísticas e culturais tipicamente brasileiras.

Além de compor o incipit do texto, representado pela experiência do exílio profundamente relevante para a produção do manuscrito - tanto que o próprio Freyre define-o "o tipo ideal de viagem para os estudos e as preocupações que este ensaio reflete" (FREYRE, 1954, p. 15) -, a valorização do assunto do livro e o acompanhamento a uma boa leitura podem ser enfatizados como os principais objetivos a que Freyre se propõe nesta instância. Ela prossegue em uma espécie de excurso da própria vida e dos estudos do autor, que leva o leitor até a "revelação" do tema a ser analisado, ou seja, "as relações entre os brancos e 'as raças de cor', a partir do século XVI, condicionadas principalmente pela produção econômica e pela falta de mulheres brancas entres os conquistadores" (FREYRE, 1954, p. 19).

Prosseguindo, no prefácio escrito por Gilberto Freyre especificamente para o público italiano, o autor inicia demonstrando grande entusiasmo pela aparição da tradução em língua italiana, sentimento que provavelmente justifica a presença deste elemento paratextual. O mesmo tinha acontecido com a versão estadunidense, mas não com a francesa. Desde as primeiras linhas, apresenta-se o objetivo principal da obra, que

consiste na análise e interpretação do homem civil situado em uma área tropical: seu contato de europeu tirado da Europa, com a natureza, as populações e as culturas tropicais; sua ação sobre elas; sua modificação baseada em tais fatores até tornar-se um terceiro "homem": nem europeu, nem tropical, mas uma combinação de ambos em uma expressão nova do ponto de vista físico e, sobretudo, sociológico. O processo formativo deste tipo de homem aconteceu de maneira notável no Brasil que, entre as áreas tropicais mais importantes é talvez aquela onde a presença 
italiana foi mais vivaz e forte (FREYRE, 1965, p XIII). ${ }^{9}$

Apesar de não existirem elementos concretos que possam demonstrar uma troca de ideias entre o autor e o tradutor, é possível supor que os dois intelectuais se conhecessem, pois Alberto Pescetto, de 1947 a 1951, foi professor de italiano em algumas universidades americanas. O próprio Freyre chama-o de professor no prefácio escrito em ocasião da sua tradução de Nordeste (FREYRE, 1970, p. 9) e de Case e catapecchie em 1972, e chega a declarar que foi o italiano a lhe sugerir "adicionar alguma palavra introdutória à edição que [...] aparece neste ilustre idioma latino" (FREYRE, 1972, p. XI).

Continuando com a apresentação dos discursos de acompanhamento, Fernand Braudel, em sua introdução (para o público italiano), define a obra como um "sucesso raro e impactante" (BRAUDEL, 1965, p. IX), ${ }^{10}$ estabelecendo um contato direto com o leitor e introduzindo ao público italiano tanto a obra quanto o autor, além do contexto brasileiro da primeira metade dos anos 1900:

Em 1933 Casa-grande e senzala vem à luz em um Brasil doente, como o mundo daquela época, sofrendo em sua vida material, em sua realidade política, intelectual. O novo livro, de finíssima escrita, fez logo escândalo: o Brasil daqueles anos queria ser Europa e colocava-se do lado dos patrões, dos brancos. Lembro uma resenha bastante acre, publicada naquele mesmo ano em São Paulo. Como admitir aquela linguagem, aquele casamento entre raças: a branca, a "vermelha", a africana (está bem, a indiana, mas a negra!)? Como aceitar aquela negação de uma luta entre classes e entre peles de diversas cores, em nome de uma

\footnotetext{
9 “'Consiste nell' analisi ed interpretazione dell'uomo civile situato in una area tropicale: il suo contatto di europeo sradicato dall'Europa colla natura, le popolazioni e le culture tropicali; la sua azione su di esse; la sua modificazione in base a tali fattori sino a divenire un "terzo uomo": né europeo né tropicale, ma una combinazione di entrambi in un'espressione nuova dal punto di vista fisico e soprattutto sociologico. Il processo formativo di questo tipo d'uomo è venuto svolgendosi in modo notevole nel Brasile, che, tra le aree tropicali più importanti è forse quella in cui la presenza italiana è stata più vivace e forte" (Tradução minha).

10 "successo tanto raro e bruciante" (Tradução minha).
} 
geral e reconhecida promiscuidade das relações sexuais? O senhor de engenho conhece demasiado bem o caminho para as senzalas, as vizinhas casas dos seus escravos. Seus filhos, negros e brancos ou, melhor, mestiços e brancos, eram criados todos juntos nas casas grandes. Aquele sangue misturado marcou, pouco a pouco, insidiosamente, todos os homens e todas as mulheres do Brasil norteocidental, criando um paraíso erótico onde, enfim, cada um achou seu porto, suas vantagens, sua consolação. [...] Difícil explicar melhor: percorrer os livros de Gilberto Freyre dá um grande prazer concreto e físico, como viajar em sonho para países tropicais e luxuriantes do Rousseau. Mas é também um prazer intelectual (BRAUDEL, 1965, p. IX-X). ${ }^{11}$

Entrando na viva discussão sobre escolhas tradutórias, neste mesmo trecho intervém o tradutor, Alberto Pescetto, ressaltando em itálico a presença de alguns termos bastante representativos do contexto brasileiro, sem algum tipo de nota explicativa, deixando ao glossário esta função. $\mathrm{O}$ exemplo por excelência no texto protagonista deste artigo é a senzala, um dos topônimos mais emblemáticos da identidade cultural

11 "Nel 1933 Padroni e schiavi veniva alla luce in un Brasile malato, come il mondo di allora, sofferente nella sua vita materiale, nella sua realtà politica, intellettuale. Il nuovo libro, di finissima scrittura, fece subito scandalo: il Brasile di quegli anni voleva essere Europa e si collocava dalla parte dei padroni, dei bianchi. Ho sotto gli occhi una recensione assai acre, pubblicata in quello stesso anno a São Paulo. Come ammettere quel linguaggio, quel matrimonio fra tre razze: la bianca, la «rossa», l'africana (e passi ancora l'indiana, ma la nera!)? Come accettare quella negazione di una lotta tra classi e fra pelli di vario colore, in nome di una generale e riconosciuta promiscuità dei rapporti sessuali? Il senhor de engenho conosce anche troppo bene la via delle senzalas, le case vicine dei suoi schiavi. I suoi figli, neri e bianchi, o meglio meticci e bianchi, erano allevati tutti insieme nella grande dimore coloniali. Quel sangue misto ha marcato, a poco a poco, insidiosamente, tutti gli uomini e tutte le donne del Brasile nord-occidentale, creando un paradiso erotico in cui alla fine ognuno ha trovato il suo porto, il suo tornaconto, la sua consolazione. [...] Difficile dir meglio: percorre i libri di Gilberto Freyre dà un piacere concreto, fisico, come viaggiare in sogno nei paesaggi tropicali e lussureggianti del Doganiere Rousseau. Ma è anche un piacere intellettuale di una qualità eccezionalmente rara" (Tradução minha). 
brasileira de origem africana, ${ }^{12}$ presente no título original da obra e ligado à época da escravidão.

A senzala é definida no glossário como "abitazione degli schiavi: da una parola bantù che significa dimora" (FREYRE, 1965, p. 533). ${ }^{13}$ O sociólogo Roger Bastide, analogamente, define assim a senzala: "Habitations des esclaves (vient d'un mot bantou, qui signifie demeure)" (FREYRE, 1952, p. 548), ${ }^{14}$ enquanto no glossário criado por Samuel Putnam a definição é: "The quarters where the slaves lived in a plantation" (FREYRE, 1946, p. 497), ${ }^{15}$ infelizmente sem nenhuma referência à origem africana do termo, como aparece na tradução italiana e francesa. É evidente que a definição do termo em italiano foi elaborada a partir das definições presentes nos glossários das duas traduções nomeadas (a inglesa e a francesa).

O papel ativo do tradutor (VENUTI, 1999) é neste paratexto muito mais evidente que no texto em si, e demonstra o fato de que todo o aparato paratextual detém uma importância fundamental para a obra. De fato, devido à dificuldade de transpor alguns conceitos particularmente carregados de significado, do sistema linguístico e cultural brasileiro ao italiano, Alberto Pescetto cumpre uma operação pioneira neste campo, ou seja, afirmar ter utilizado outros textos já produzidos em outros sistemas linguísticos para enriquecer o próprio: "Este glossário foi criado a partir da colação de diversos dicionários brasileiros com o texto de repertórios análogos nas edições francesa e inglesa de Padroni e schiavi [nota do tradutor]" (PESCETTO, 1965, p. 522). ${ }^{16}$ Ele mantém, todavia, as caraterísticas de criatividade e originalidade atribuíveis ao processo tradutório: de fato não existia, até aquele momento, na língua-alvo, aquela obra, escrita com aquelas palavras, e aquelas determinadas construções.

\footnotetext{
${ }^{12}$ Segundo afirmado por Luis da Câmara Cascudo no Dicionário do folclore brasileiro (1954).

13 "Habitação dos escravos: de uma palavra banto que significa moradia" (Tradução minha).

14 "Habitação dos escravos (vem de uma palavra banto que significa moradia)". (Tradução minha).

15 "Lugares onde vivem os escravos nas plantações" (Tradução minha).

16 "Questo glossario è stato stabilito mediante collazione di diversi dizionari brasiliani col testo di analoghi repertori nelle edizioni francese ed inglese di Padroni e schiavi [N.d.T.]" (Tradução minha).
} 
É também sempre necessário contextualizar, em nível histórico e cultural, a produção de um texto traduzido e, portanto, também o do glossário. Na prática, se por um lado alguns dos termos não aparecem frequentemente no texto, sua presença no glossário resulta de grande importância para uma aproximação do leitor italiano, sobretudo no caso dos itens que possuem uma relevância temática e linguística, portadores da cultura do texto-base (TOROP, 2010, p. 215).

Entre os numerosos termos presentes no texto freyriano que despertaram maior interesse, pela complexidade e particularidade do significado que carregam em língua portuguesa, muitos provêm de outras línguas e foram incluídos na língua brasileira tornando-se a forma mais idônea de expressão cultural do Brasil, assim como afirma o próprio Freyre (1965, p. 294, grifos do autor):

Certamente as maiores diferenças entre o português do Brasil e o de Portugal não derivam todas da influência africana: os indígenas, os "ciganos", os "espanhóis", deram sua contribuição e João Ribeiro adiciona também o influxo do "clima das novas necessidades, prospectivas, coisas, indústrias". Mas a influência negra foi a mais forte [...]. Qual brasileiro, pelo menos do norte, sente algum tipo de exotismo em palavras como: caçamba, canga, dengo, cafuné, lubambo, mulambo, caçula, quitute, mandinga, muleque, camondongo, muganga, cafajeste, quibebe, quengo, batuque, banzo, mucambo, bangüe, bozó, mocotó, bunda, zumbi, vatapá, caruru, banzé, jiló, mucama, quindim, catinga, mugunzá, malungo, birimbau, tanga, cachimbo, candomblé? [...] São palavras que correspondem, melhor das portuguesas, à nossa experiência, paladar, sentidos, emoções. ${ }^{17}$

\footnotetext{
17 'È certo che le differenze sempre più grandi fra il portoghese del Brasile e quello del Portogallo non derivano tutte dall'influenza africana: gli indigeni, 'gli zingari', 'gli spagnoli', vi hanno la loro parte, e João Ribeiro vi aggiunge pure l'influsso del 'clima, dei nuovi bisogni, prospettive, cose, industrie'. Ma l'influenza negra fu la più forte $[\ldots]$. Quale brasiliano, per lo meno settentrionale, sente alcun esotismo in parole come caçamba, canga, dengo, cafuné, lubambo, mulambo, caçula, quitute, mandinga, muleque, camondongo, muganga, cafajeste, quibebe, quengo, batuque, banzo, mucambo, bangüê, bozó, mocotó, bunda, zumbi, vatapá, caruru, banzé, jiló, mucama, quindim, catinga, mugunzá, malungo, birimbau, tanga, cachimbo, candomblé? [...] Sono parole che corrispondono meglio di quelle portoghesi alla nostra esperienza, palato, sensi, emozioni" (Tradução minha).
} 
De todas essas expressões da identidade cultural brasileira, aqui serão apresentadas somente algunas, extraídas destes discursos de acompanhamento presentes na versão italiana da obra-prima freyriana, como os dois antônimos que formam o título original da obra, a casagrande e a senzala, que junto ao sobrado e ao mocambo (que dão título ao segundo volume da trilogia freyriana) representam a evolução urbana da sociedade brasileira, da patriarcal até a urbana. Se pensamos, por exemplo, o estudo dos edifícios como expressão cultural, ou melhor, ação das sociedades humanas que transformam o espaço natural em espaço social (ou geográfico), sendo que, atualmente, não existe espaço geográfico sem as sociedades e suas histórias (cf. VISCONTI, [s.n.t.]), compreendemos a motivação de Freyre ao atribuir tanta importância aos termos presentes no título em português. Esta escolha pode ser associada ao estilo narrativo do autor que, frequentemente, associa realidades muito diferentes, sobretudo para a escolhas dos títulos, descrevendo com grande minúcia de detalhes todas as nuances da realidade brasileira nas suas produções.

Em relação ao termo casa-grande, antes de tudo, este não aparece na lista de vocábulos inseridos no glossário de Padroni e schiavi provavelmente pela aproximação linguístico-fonética com o italiano - , nem aparece nas traduções estadunidense e francesa. Portanto, o termo continua igual, com a introdução, ao longo do texto, de diversos sinônimos, a saber: casa padronale (FREYRE, 1965, p. 426), grande villa (FREYRE, 1965, p. 430), grande casa rurale (FREYRE, 1965, p. 435) e, enfim, grande abitazione da piantagione (FREYRE, 1965, p. 436); fato que, sem dúvida, dá origem a uma distorção do termo. Em verdade, o que este complexo habitacional representa, além de mera morada, é muito complexo. A partir do século XVI, a casa-grande representou a residência dos grandes proprietários de terras rurais do Brasil colonial. Tudo acontecia ao redor da casa-grande, como centro da organização social, política e econômica local. Construídas estrategicamente perto do engenho propriamente dito, da senzala e da capela, praticamente produziam tudo aquilo que os donos e os escravos consumiam:

Nos engenhos, viviam os amos e seus familiares, alguns moradores e agregados e, em média, uns oitenta cativos. Nos mais ricos, as instalações produtivas e as residências eram de tijolo e pedra. Nos mais pobres, de pau-a-pique, taipa de pilão, e coberturas de sapé. A casa-grande 
era construída num ponto alto e sadio, de modo que se pudessem controlar a senzala e os canaviais. Nela, residiam a família senhorial, alguns agregados e os cativos mais próximos dos amos. As casas-grandes dos maiores engenhos eram sobrados com inúmeras peças dormitórios, refeitórios, cozinhas, despensas, lavanderias, adegas, etc. (MAESTRI, 1994, p. 73).

Em relação ao termo senzala, as reflexões são ainda mais significativas, devido à sua origem africana e à importância cultural que carrega. Se por um lado, como antecipado, Alberto Pescetto insere o vocábulo no glossário, por outro, para o texto-meta ele parece não elaborar uma estratégia específica, traduzindo o termo de diferentes maneiras, colocando, somente esporadicamente, a palavra em português, em itálico (FREYRE, 1965, p. 273; 294) ou entre parênteses (FREYRE, 1965, p. 426). Alguns exemplos de tradução são: "fattoria negra" (FREYRE, 1965, p. 215), "stamberga” (FREYRE, 1965, p. 294), “dimora per gli schiavi” (FREYRE, 1965, p. 426), "capanna” (FREYRE, 1965, p. 428), "schiavo" (FREYRE, 1965, p. 428), "reparto schiavi” (FREYRE, 1965, p. 430), "negro" (FREYRE, 1965, p. 434), “dipendenze per i Negri” (FREYRE, 1965, p. 435), "capanne della piantagione” (FREYRE, 1965, p. 441). Esta operação, sem dúvida, enfraquece o valor que o próprio Freyre atribui ao termo, que sofre uma evidente perda semântica que, de alguma forma, silencia a antiga voz dos escravos africanos cujos descendentes, também através da senzala, podiam manter viva a peculiaridade da própria identidade. De fato, estudos recentes afirmam que se, por um lado, o maior choque da escravidão tenha sido, além do medo da violência física e da morte em si, o implacável ataque à própria identidade, por outro, foi este aspecto mesmo, o mais degradante, que "incentivou os escravos a cultivar, justamente, uma maior apreciação às mais pessoais e humanas caraterísticas que diferenciam um indivíduo do outro, o que talvez representem as principais qualidades das quais o branco não podia privá-los" (MINTZ; PRICE, 2003, p. 75).

Se, de um lado, é evidente, para o público brasileiro, que a casa-grande e a senzala representam dois elementos extremamente paradigmáticos do sistema patriarcal brasileiro, além de um exemplo por excelência da influência linguística africana na língua portuguesa, de outro, é patente que esses não são tão óbvios nos contextos europeus: 
o francês e o italiano, no caso. É possível afirmar que, por essa razão, na época da primeira publicação (segunda metade do século XX) o título Casa-grande e senzala não teria funcionado. Isso justifica, de alguma forma, a entrega passiva dos dois tradutores europeus à escolha tomada, de forma ciente, entretanto, pelo tradutor estadunidense, Samuel Putnam. É preponderante a falta, para o público europeu (francês e italiano, especificamente), daquelas referências históricas e culturais ligadas à escravidão que, ao contrário, o leitor estadunidense detém devido ao recente passado escravocrata. Diversamente, a escolha de Benjamin de Garay, autor da primeira tradução da obra-prima freyriana, é a de manter os dois termos dicotômicos do título em português: Casa-grande y senzala.

Essas escolhas tradutórias representam, com certeza, o resultado de reflexões mais ou menos teóricas e de estratégias editorias devidamente pensadas, que refletem o objetivo de produzir textos-metas diferentes, dependendo de seu contexto geográfico e cultural. As estratégias tradutórias, assim como apresentadas por Mona Baker (1998), ajudam (com os elementos paratextuais) a reconstruir a formação cultural na qual a tradução foi produzida e divulgada, e dividem-se principalmente em estratégias de domesticação e de estranhamento. No primeiro caso o texto estrangeiro é interpretado segundo os valores da língua de chegada, eliminando-se as diferenças que a tradução é chamada a transmitir; no segundo caso estas diferenças são enfatizadas, valorizadas, dando ao texto o caráter de tradução (BAKER, 1998, p. 240-244).

De alguma forma, trata-se de manter o ponto de vista que o autor nordestino quer enfatizar na própria interpretação sociológica da formação do Brasil, em toda a sua complexidade. Não se trata, a seu ver, somente da representação da dicotômica relação entre o dono e o escravo, mas do simbolismo ligado ao antagonismo e à distância social entre duas categorias sociológicas, evidenciado a partir do tipo de habitação destinada a cada um destes dois grupos que representaram o Brasil de 1500 até 1800 e não somente como donos e escravos, brancos e negros, europeus e africanos: "Extremos que dão o nome às suas obras e que não podem ser subestimados" (LOSANO, 2008, p. 7). ${ }^{18}$

18 "Estremi che danno il nome alle sue opere e che non possono essere sottovalutati" (Tradução minha). 
Apesar de não entrar nos termos de origem africana, outro item apresentado pela importância cultural que representa é sertão, vocábulo lusófono que pertence à nação brasileira. Ausente no texto-meta, é assim definido no glossário: “etimologicamente 'il deserto', l'interno del paese ancora spopolato e quasi selvaggio" [etimologicamente 'o deserto', o interior do país ainda despovoado e quase selvagem] (FREYRE, 1965, p. 533, tradução minha), sem nenhuma referência geográfica ou cultural.

Se, por um lado, a ausência do termo dentro do texto-meta resulta, sem dúvida, mais fácil de justificar, à luz de um evidente gap fonético do termo, devido ao som - ão, inexistente na fonética italiana (justificação inutilizável em relação a senzala), por outro, apesar da sua presença no glossário, o termo é empobrecido na obra de 1965, ao ser traduzido, indiferentemente, como "deserto", "selva" ou "regione selvaggia", sem nenhuma referência, por exemplo, a algum elemento da geografia italiana, ou europeia, ao qual poderia ter sido associado.

Ao se aprofundar mais a análise da presença, nos paratextos selecionados, de alguns topônimos de origem africana que representam elementos culturais no texto freyriano e que, diversamente de senzala e sertão, encontraram um lugar na tradução italiana, o vocábulo mocambo (ou mucambo) parece ser o mais significativo para ser apresentado. Mocambo é um termo bem representativo da segunda obra que pertence à trilogia freyriana: Sobrados e mucambos. Decadência do patriarcado e desenvolvimento do urbano (1936), traduzido para o italiano quase quarenta anos depois com o título Case e catapecchie. La decadenza del patriarcato rurale brasiliano e lo sviluppo della famiglia urbana (1974).

Ao contrário de senzala, mocambo é inserido no texto-meta dos anos 1970, no qual o tradutor opta por mantê-lo em português, ressaltando-o em itálico. Isso leva a supor que, na terceira tradução da obra freyriana, o tradutor atingiu um grau de maturidade tal que lhe permitiu dar a importância certa aos termos que dão título à obra em português. Apesar disso, provavelmente por razões editoriais, o vocábulo não está presente no título italiano, mas, pelo menos, aparece no textometa em itálico, assim como muitos outros, silenciados, por sua vez, em Padroni e schiavi.

O mocambo, no glossário de Padroni e schiavi, é da seguinte forma definido: "vedi Mucambo. Dal bantú mu-kambre: nascondiglio" [ver Mucambo. Do bantu mu-kambre: esconderijo] (FREYRE, 1965, p. 530, grifo do tradutor, tradução minha). Com referência à origem africana 
do termo: "Mucambo: la capanna dei negri. Quindi il luogo di rifugio dei negri fuggiaschi" [Mucambo: a cabana dos negros. Portanto, lugar de abrigo para os negros fugitivos] (FREYRE, 1965, p. 530, tradução minha). Isso leva a supor que o tradutor ainda não tivesse chegado a uma definição específica, como no caso de senzala.

Nos anos 1970, em Nordeste, Alberto Pescetto completa a definiçao: "MUCAMBO ovvero mocambo, recinto di schiavi nella foresta o rifugio di schiavi fuggiaschi. Donde capanna in genere e, gradualmente, catapecchia o tugurio urbano" [MUCAMBO, ou seja, mocambo, recinto de escravos na floresta ou abrigo de escravos fugitivos. Donde cabana em geral e, gradualmente, barraco ou tugúrio urbano] (FREYRE, 1970, p. 214). Dois anos depois, na edição que o contém o vocábulo no título, ele é assim definido:

Mucambo ovvero mocambo: rifugio di schiavi nella foresta, sinonimo di quilombo. (Cfr. voce corrispondente in Glossario della traduzione italiana di Padroni e schiavi). Nel Nord Brasile indica pure il folto del bosco dove si nasconde il bestiame. Altresì una capanna o abituro rustico. Da cui, estensivamente, il significato-chiave, peraltro generico, che il vocabolo assume nel presente trattato: abitazione di vita primitiva e umile, antitetica della dimora signorile urbana (sobrado) e tipica della gente di colore (FREYRE, 1972, p. 753). ${ }^{19}$

Comparando esta com a definição dada sete anos antes em ocasião da publicação de Padroni e schiavi, percebe-se um enriquecimento semântico, com a apresentação de mais detalhes, confirmando a hipótese de que quanto mais Alberto Pescetto imerge na tradução das obras freyrianas, maior é sua consciência do valor semântico-cultural

\footnotetext{
19 “"Mucambo, ou seja, mocambo: refúgio de escravos na floresta, sinônimo de quilombo (cf. verbete correspondente no Glossário da tradução italiana de Padroni e schiavi). No Norte do Brasil, indica também a frondosidade do bosque onde esconde-se o gado. Também cabana ou habitação rústica. Daqui, por extensão, o significado-chave, além disso genérico, que o termo assume neste tratado: habitação de vida primitiva e humilde, antitética à demora senhoril urbana (sobrado) e típica das pessoas de cor" (Tradução minha).
} 
destes termos. É possível afirmar, a respeito, que o mocambo está para a senzala como a casa-grande está para o sobrado. Esses termos podem ser considerados os mais representativos das duas principais obras traduzidas para o italiano por Alberto Pescetto, e consideradas duas obras-primas que descrevem a imensidade de um país como o Brasil, através da ciência e da arte:

Colocando-se, de fato, frente aos multíplices problemas cujo conjunto representa a imensa vida que se chama Brasil, Freyre foi fazendo, com a preparação de cientista e com intuição de artista, um exame tão corajoso e sistemático da história social do próprio país, que em poucos anos revolucionaram sua consciência e sua avaliação. Esta história, vista por Freyre, é exposta sobretudo em três livros que formam uma trilogia ideal. Casa Grande e Senzala examinou a formação do povo brasileiro de hoje, corajosamente expondo, com estilo simples e dramático que apresenta as questões mais difíceis para o vasto público como o romance de um grande romanceiro, o choque e, junto, a fusão dos três mundos de onde surgiu a 'brasilianidade': o ameríndio, o português (e europeu em geral, começando do italiano) e o africano. Sobrados e Mucambos examinou, ao contrário, a sociedade brasileira, já constituída, na sua evolução segundo as leis dos organismos coletivos, preocupando-se em manter a atenção do leitor e do estudioso nas influências que, de tal organismo, vem de sua recente formação, com virtudes e defeitos de um sangue jovem e ao mesmo tempo excepcionalmente rico de energia para os multíplices e diversíssimos elementos cuja fusão lhe deu origem (ROSSI, 1949, p. 380). ${ }^{20}$

20 "Postosi difatti di fronte ai molteplici problemi il cui insieme rappresenta l'immensa vita che si chiama Brasile, il Freyre è andato facendo, con preparazione di scienziato e con intuizione di artista, un esame così coraggioso e sistematico della storia sociale del suo paese, che in pochi anni ne ha rivoluzionato la conoscenza e la valutazione. Tale storia, quale il Freyre l'ha vista, è esposta soprattutto in tre libri che formano una trilogia ideale. Casa Grande e Senzala ha esaminato la formazione del popolo brasiliano d'oggi, coraggiosamente esponendo, con stile semplice e drammatico che presenta le questioni più difficili per il gran pubblico come un romanzo da grande romanziere, 
Para concluir, é possível afirmar que Padroni e schiavi é um texto principalmente informativo, caraterizado por escolhas empíricas, como a inserção de regionalismos e brasileirismos no glossário traduzido. Em outros casos, o significado de palavras específicas é ampliado e a mesma palavra é frequentemente traduzida por diferentes sinônimos, como a própria senzala, com perdas semânticas referentes aos aspectos sociológicos - a começar pelo título traduzido, que se refere a uma imagem medieval, devido à falta de referências históricas e culturais sobre a escravidão. Portanto, as estratégias utilizadas na tradução italiana de Casa-grande e senzala refletem, de forma equilibrada, elementos domesticadores, quando o texto flui e quase se confunde com os valores da cultura de chegada, e elementos que, ao contrário, provocam certo estranhamento, por exemplo, quando são mantidos os termos em língua portuguesa, além da presença do glossário.

Essas escolhas são justificáveis como estratégias editoriais voltadas à difusão da reflexão teórica mais geral defendida por Gilberto Freyre, na contramão das teorias racistas que se difundiram na Europa na primeira metade do século XX.

Este artigo pretendeu demonstrar a importância e a utilidade dos elementos que vão além do texto em si, mas que estão a sua margem, quer se trate de tradução ou não, através da valorização dos elementos paratextuais presentes na tradução italiana de Casa-grande e senzala. Estes envolvem, de fato, a escolha do texto estrangeiro a ser traduzido, além do desenvolvimento de uma metodologia usada para traduzi-lo. No caso específico de Padroni e schiavi, há uma riqueza de paratextos que permitiu evidenciar algumas escolhas do tradutor e da editora, agentes ativos no processo tradutório, ressaltando também o espaço ocupado por elementos culturais e políticos neste mesmo processo.

l'urtarsi e insieme il fondersi dei tre mondi da cui è sorta la 'brasilianità': l'amerindio, il portoghese (ed europeo in genere, a cominciare dall'italiano) e l'africano. Sobrados e Mucambos ha esaminato invece la società brasiliana, già costituita, nel suo evolversi secondo le leggi degli organismi collettivi, badando a tenere fissa l'attenzione del lettore e dello studioso sulle influenze che, a tale organismo, vengono dalla sua formazione recente, con virtù e difetti di un sangue giovane e allo stesso tempo eccezionalmente ricco di energie per i molteplici e diversissimi elementi la cui fusione l'ha originato" (Tradução minha). 


\section{Referências}

BAKER, Mona (Ed.). Routledge encyclopedia of Translation Studies. London, New York: Routledge, 1998.

BRAUDEL, Fernand. Introduzione di Fernand Braudel. In: FREYRE, Gilberto. Padroni e schiavi: la formazione della famiglia brasiliana in regime di economia patriarcale. Tradução de Alberto Pescetto. Torino: Giulio Einaudi, 1965. p. IX-XI.

CANDIDO, Antonio. O significado de "Raízes do Brasil". HOLANDA, Sérgio Buarque de. Raizes do Brasil. São Paulo: Cia. das Letras, 1995. p. 9-21.

CASCUDO, Luis da Câmara. Dicionário do folclore brasileiro. Rio de Janeiro: Ministério da Educação e da Cultura, Instituto Nacional do Livro, 1954.

CELARENT, Barbara. The masters and the slaves by Gilberto Freyre. American Journal of Sociology, Chicago, v. 116, n. 1, p. 334-339, July 2010. Disponível em: <www.jstor.org/stable/10.1086/655749>. Acesso em: 10 fev. 2016.

CHACON, Vamireh. A construção da brasilidade: Gilberto Freyre e sua geração. Brasília: Paralelo 15; São Paulo: Marco Zero, 2001.

CHEROBIN, Nicoletta. (La) Casa-grande e (la) senzala brasiliana tradotta in italiano: analisi paratestuale di Padroni e schiavi. 2015. Tese (Doutorado em Estudos da Tradução) - Centro de Comunicação e Expressão, Universidade Federal de Santa Catarina, Florianópolis, 2015. 2 v. Disponível em: < https://repositorio.ufsc.br/bitstream/ handle/123456789/158426/336881. .pdf? sequence $=1$ \&isAllowed $=y>$. Acesso em: 15 jan. 2016.

DAVID, Michel. L'immaginario della biblioteca: scritti letterati. Roma: Aracne Editrice, 2012. Disponível em: <http://www.aracneeditrice.it/ pdf/9788854847668.pdf $>$. Acesso em: 15 jan. 2016.

EINAUDI. Le edizioni Einaudi negli anni 1933-2003. Torino: Einaudi Editore, 2003.

FREYRE, Gilberto. Brazil, an interpretation. New York:Alfred A. Knopf, 1945a.

FREYRE, Gilberto. Casa-grande \& senzala: formação da família brasileira sob o regime de economia patriarcal. Rio de Janeiro: Maia \& Schmidt, 1933. 
FREYRE, Gilberto. Casa-grande y senzala. Formacion de la familia brasileña bajo el regimen de econ(FREYRE, 1965, p. IX)omia patriarcal. Tradução de Benjamin De Garay. Buenos Aires: Biblioteca de Autores Brasileños Traducidos al Castellano, 1942.

FREYRE, Gilberto. Case e catapecchie: la decadenza del patriarcato rurale brasiliano e lo sviluppo della famiglia urbana. Traduçção de Alberto Pescetto. Torino: Giulio Einaudi, 1972.

FREYRE, Gilberto. Interpretazione del Brasile. Tradução de Franco Lo Presti Seminerio. Milano: Fratelli Bocca, 1954.

FREYRE, Gilberto. Maîtres et esclaves: la formation de la société brésilienne. Tradução de Roger Bastide. Paris: Gallimard, 1952.

FREYRE, Gilberto. Nordeste: aspectos da influência da cana sobre a vida e a paisagem do Nordeste do Brasil. Rio de Janeiro: José Olympio, 1937.

FREYRE, Gilberto. Nordeste: l'uomo e gli elementi. Traduçção de Alberto Pescetto. Milano: Rizzoli, 1970.

FREYRE, Gilberto. Padroni e schiavi: la formazione della famiglia brasiliana in regime di economia patriarcale. Tradução de Alberto Pescetto. Torino: Giulio Einaudi, 1965.

FREYRE, Gilberto. Sobrados e mucambos: decadência do patriarcado rural e desenvolvimento do urbano. São Paulo: Companhia Editora Nacional, 1936.

FREYRE, Gilberto. Sociologia della medicina: breve introduzione allo studio dei suoi principi, metodi e con altre sociologie e altre scienze. Tradução de Alberto Pescetto. Milano: Rizzoli, 1975.

FREYRE, Gilberto. Sociologia: introdução ao estudo dos seus princípios. Rio de Janeiro: José Olympio, $1945 \mathrm{~b}$.

FREYRE, Gilberto. The masters and the slaves: a study in the development of Brazilian civilization. Tradução de Samuel Putnam. New York: Alfred, A. Knopf, 1946.

GENETTE, Gérard. Soglie. I dintorni del testo. Tradução de Camilla Cederna. Torino: Einaudi, 1989.

GENTZLER, Edwin. Teorie della traduzione, tendenze contemporanee. Tradução de Maria Teresa Musacchio. [S.1.]: UTET Libreria, 1998.

HOLANDA, Sérgio Buarque de. Raizes do Brasil. São Paulo: Cia. das Letras, 1995. 
LOSANO, Mario G. Ambigui tropici: la multietnicità felice di Gilberto Freyre e l'ultimo colonialismo portoghese. Teoria Politica, Torino, n. 1, p. 5-45, 2008. Disponível em: <http://dialnet.unirioja.es/ejemplar/195042>. Acesso em: 3 jan. 2016.

MAESTRI, Mário. O escravismo no Brasil. São Paulo: Atual, 1994.

MINTZ, Sidney W.; PRICE, Richard. O nascimento da cultura afroamericana: uma perspectiva antropológica. Tradução de Vera Ribeiro. Rio de Janeiro: Pallas, 2003.

PESCETTO, Alberto. Nota do tradutor. In: FREYRE, Gilberto. Padroni e schiavi: la formazione della famiglia brasiliana in regime di economia patriarcale. Tradução de Alberto Pescetto. Torino: Giulio Einaudi, 1965. p. 521-522.

ROSSI, Giuseppe Carlo. Interpretação do Brasil. São Paulo: Livraria José Olympio Editora, 1947. Rivista Idea, Roma, n. 5, v. 6, p. 380-381, 1949.

TOROP, Peeter. La traduzione totale. Tradução de Bruno Osimo. Milano: Hoepli, 2010.

TORRES, Marie-Hélène Catherine. Traduzir o Brasil literário. Tradução de Marlova Aseff e Eleonora Castelli. Tubarão: Copiart, 2011.

VENUTI, Lawrence. L'invisibilità del traduttore: una storia della traduzione. Tradução de Marina Guglielmi. Roma: Armando Editore, 1999.

VISCONTI, Agnese. Geografia antropica. [s.n.t.]. Apostila. Disponível em: <http://www-3.unipv.it/iscr/programmi_dispense_02_03/ scienze/visconti/geografia.doc>. Acesso em: YŪSTE FRÍĀS, José. Deconstrucción, traducción y paratraducción en la era digital. In: YUSTE FRÍAS, José; LUGRIS ÁLVAREZ, Alberto (Ed.). Tradución e paratradución. Vigo: Servizo de Publicación da Univerdidade de Vigo, 2005. p. 59-84. (Colección Traducción \& Paratraducción).

YUSTE FRÍAS, José. Au seuil de la traduction: la paratraduction. In: NAAIJKENS, Ton (Ed.). Event or incident. On the role of translation in the dynamics of cultural exchange. / Événement ou incident. Du rôle des traductions dans les processus d'échanges culturels. Bern, Berlin, Bruxelles: Frankfurt am Main; New York, Oxford, Wien: Peter Lang, 2010. v. 3. (Genèses de Textes-Textgenesen). Disponível em: $<$ http://www.joseyustefrias.com/index.php/publicaciones/capitulos-delibro/174-informacion.html>. Acesso em: 22 jan. 2016. 